\title{
Comment on 'A Semi-Analytical Solution for Large-Scale Injection-Induced Pressure Perturbation and Leakage in a Laterally Bounded Aquifer-Aquitard System' by Quanlin Zhou, Jens T. Birkholzer and Chin-Fu Tsang, Transport in Porous Media, doi:10.1007/s11242-008-9290-0
}

\section{E. J. M. Veling}

Received: 19 October 2010 / Accepted: 27 October 2010 / Published online: 17 November 2010

(C) The Author(s) 2010. This article is published with open access at Springerlink.com

In the paper 'A Semi-Analytical Solution for Large-Scale Injection-Induced Pressure Perturbation and Leakage in a Laterally Bounded Aquifer-Aquitard System' by Quanlin Zhou, Jens T. Birkholzer and Chin-Fu Tsang, Transport in Porous Media (2009), vol. 78, pp. 127-148 (doi:10.1007/s11242-008-9290-0) the authors study nicely the influences of pressure perturbations on a system of an aquifer and an overlying or underlying aquitard. In the sequel, we denote by $\mathrm{Zh}(i)$ equation $(i)$ in their paper.

In this Comment, we shall point out a serious mistake in the derivation of their results. The authors scale their dependent $\left(h, h^{\prime}\right)$ and independent variables $(r, z$ and $t)$ and subtract from $h(r, t)$ (head in the aquifer) and $h^{\prime}(r, z, t)$ (head in the aquitard) the corresponding initial conditions $h_{i}(r), h_{i}(r, z)$, respectively, as

$$
\begin{aligned}
h_{D}\left(r_{D}, t_{D}\right) & =\frac{4 \pi K B}{Q}\left(h(r, t)-h_{i}(r)\right), \quad \text { for the aquifer, } \mathrm{Zh}(3), \\
h_{D}^{\prime}\left(r_{D}, z_{D}, t_{D}\right) & =\frac{4 \pi K B}{Q}\left(h^{\prime}(r, z, t)-h_{i}^{\prime}(r, z)\right), \quad \text { for the aquitard, } \mathrm{Zh}(3) .
\end{aligned}
$$

Indeed, now they have

$$
\begin{aligned}
h_{D i}\left(r_{D}\right) & =h_{D}\left(r_{D}, 0\right)=\frac{4 \pi K B}{Q}\left(h(r, 0)-h_{i}(r)\right)=0, \quad \text { for the aquifer, } \mathrm{Zh}(4 \mathrm{e}), \\
h_{D i}^{\prime}\left(r_{D}, z_{D}\right) & =h_{D}^{\prime}\left(r_{D}, z_{D}, 0\right) \\
& =\frac{4 \pi K B}{Q}\left(h^{\prime}(r, z, 0)-h_{i}^{\prime}(r, z)\right)=0, \quad \text { for the aquitard, } \mathrm{Zh}(5 \mathrm{~d}),
\end{aligned}
$$

but insertion of $h(r, t)$ in terms of $h_{D}\left(r_{D}, t_{D}\right)$ into $\mathrm{Zh}(1 \mathrm{a}), \mathrm{Zh}(1 \mathrm{c}), \mathrm{Zh}(1 \mathrm{~d})$ and insertion of $h^{\prime}(r, z, t)$ in terms of $h_{D}^{\prime}\left(r_{D}, t_{D}, t_{D}\right)$ into $\mathrm{Zh}(1 \mathrm{~b}), \mathrm{Zh}(2 \mathrm{a}), \mathrm{Zh}(2 \mathrm{~b}), \mathrm{Zh}(2 \mathrm{c}$, Case 2$)$ will give rise to additional terms into equations $\mathrm{Zh}(4 \mathrm{a}), \mathrm{Zh}(4 \mathrm{c}), \mathrm{Zh}(4 \mathrm{~d}), \mathrm{Zh}(4 \mathrm{~b}), \mathrm{Zh}(5 \mathrm{a}), \mathrm{Zh}(5 \mathrm{~b})$, and $\mathrm{Zh}(5 \mathrm{c}$, Case 2), respectively. In this way, the influence of the initial conditions has been 
disappeared totally, which is mathematically inconsistent. Only, if the authors should have assumed that both $h_{i}(r), h_{i}(r, z)$ were equal constants, the conclusions of the paper remain valid, but according their notation " $h_{i}(r)$ " in $\mathrm{Zh}(1 \mathrm{e})$, and in the line below $\mathrm{Zh}(2 \mathrm{c})$ " $h_{i}(r, z)$ " they apparently did not assume this simplification.

Open Access This article is distributed under the terms of the Creative Commons Attribution Noncommercial License which permits any noncommercial use, distribution, and reproduction in any medium, provided the original author(s) and source are credited. 